\title{
Infrastructure Development: Public Private Partnership Path for Developing Rural Telecommunications in Africa
}

\author{
Idongesit Williams'
}

\begin{abstract}
It is the quest of every government to achieve universal Access and service of telecommunication services and ICTs. Unfortunately due to the high cost of deploying infrastructure in rural areas of developing countries due to non-significant or no economic activity, this dream of achieving Universal access and service of telecommunications/lCTs have been stalled. This paper throws light on a possible Public Private Partnership framework as a development path that will enable affordable network technologies to be deployed in rural areas at a cost that will translate to what the rural dweller in a developing country in Africa can afford. The paper is a conceptual paper.
\end{abstract}

Keywords: public private partnership; universal access and service; telecommunications; icts; telecentre

'Center for Communication, Media and Information Technologies (CMI). Aalborg University Copenhagen, Frederikskaj 12, 3rd floor. DK-2450 Copenhagen SV. Denmark. email: idong@plan.aau.dk +457| 406394. 


\section{I.0 Introduction}

The liberalization policies of 1990s in the telecommunications industry has given rise to the new possibilities in the Information Communication Technology (ICT) sector (Melody, 20I I). The competition that ensued as a result of dissolving monopoly markets let to innovation as well as rapid adoption and diffusion of ICT services made possible by evolving telecommunications network. However, despite these developments many rural areas in the world are either unserved or underserved with telecommunication services (Dimri, 2003). Hence they can't experience the economic benefit that comes with the availability of ICTS. The major excuse network providers give as a reason for not providing full blown telecommunication services in rural areas is because these areas are not economically viable (Chauville et al, 2005). Secondly, majority of people in the rural areas live below the poverty line (Population Reference Bureau, 20I I). Hence they can't afford the same services in which their counterparts in the cities around the world do enjoy. This negates the Universal Access and Service policies adopted by various countries as a road map for granting access to telecommunication services as a means of providing ICTS nationwide.

This leads to the question of what approach can be adopted to enable people in the rural areas have access to ICTs at an affordable cost? In this paper, a Public Private Partnership (PPP) framework as a development path to access to rural telecommunications/ICTs will be discussed. This will take into consideration the financial implications of the Public Private Partnership and the organizational implications. This PPP framework is not aimed at replacing the competitive market but to stimulate the market in remote and unreached areas the where market forces alone can't. The novelty of this framework lies in the difference in approach by which the PPP operates in contrast to well-known PPP models. But before discussing the model, it is important to present an evidence of the semi-efficiency of purely the market based in developing telecommunications and how Africa has fared in contrast to the rest of the world. To make this justification, focus will be placed on the following:

\section{I.Technology drivers}

\section{Universal Access and Service policy initiatives.}

This is because -to a large extent- the development of these technology drivers is enhanced by policies with an inclination to open and competitive markets (Melody, 20II).

The global overview of what drives ICT, the current implication of the drivers is being discussed in the next section. The essence of this overview is to indicate lapses in the global approach toward Universal Access of Services. This lapse justifies the proposed PPP solution among other solutions in Africa.

\section{Global Overview of ICT Technology Drivers and its Impact in Africa}

Mobile Telephony:The major driver of ICTs of late has been mobile telephony. This became possible through the introduction of the pay-as-you go service (Kas, 2008). The market leadership of mobile telephony is evident in the International Telecommunications Union (ITU) data and statistics of October 2010, it was estimated that there were 5282 million Mobile telephony subscribers in the world. Out of this figure Africa had 333 Million subscribers, the Arab states had 282 Million Subscribers, Asia had 2649 million subscribers, the Caribbean Islands had 364 million subscribers, The European Union had 74I million subscribers and the Americas had $\mathbf{8 8 0}$ million subscribers. Comparative figures for the total number of fixed line operators globally were II 97 Million subscribers. Mobile broadband subscribers were 940 million and fixed broadband subscribers were 555 million (ITU, 20I0; Mobile thinking, 20I I).

Despite these statistics on the advancement of mobile technology as one of the major driver of ICTs of late, the Population Reference Bureau (PRB) documents that the world population is approximately 7 billion people (Population Reference Bureau, 20I I). If you pitch the 5282 Million subscribers against the 7 billion people in the world, you will have approximately $75.4 \%$ inhabitants of the world having access to mobile telephony. As population increases and economic gaps widen coupled with the recent world financial crises, there is a threat of having a slight percentage decrease in the number of actual mobile subscribers. Secondly the fact that many people worldwide have access to more than one set of mobile telephone service brings the challenge of duplicity in the attempt to carry out a census of mobile subscribers globally. Hence the actual service gap may be slightly wider. Internet: The introduction of broadband technology via fixed and mobile network technologies has led to the renewed call of focusing on the internet as a driving force for ICTs. The internet which was supposed to play the role of driving ICT couldn't do so as a result of low data transmission rate made possible by technologies that existed then (Alozie et al, 20II). However with broadband, many possibilities have emerged on the internet. The internet has moved from a 'small service box' to a box of unlimited potentials in service delivery. And as broadband speeds increase with the 3G, High Speed Packet Access (HSPA), Long Term Evolution (LTE), WiMAX and a whole lot of new technology innovation, the world is moving fast towards a digital age, where everything will be carried out electronically. As to October 2010. 
General Internet Penetration: However despite these possibilities with the internet, only The United states, Japan, Germany, The United Kingdom, France, Korea, Spain and Argentina do have more than $50 \%$ penetration rate of the internet in the world. Italy is almost there with $49.2 \%$ of penetration rate. In the same vain, only China and the United states have more than $5 \%$ percent usage of the internet with each recording $23 \%$ and $11.6 \%$ respectively. Taking a look at usage data of 20I I, the top twenty countries that use the internet the most according to their rankings are China, The United States, India, Japan, Brazil, Germany, Russia, United Kingdom, France, Nigeria, Indonesia, Korea, Iran, Turkey, Mexico, Italy, Philippines, Spain, Vietnam and Argentina. These countries account for $1,601,772,290$ of users worldwide and the rest of the world as the world account for 508,993,520 internet users. Hence the total number of internet users worldwide as at June 30,2011 was $2,110,765,810$. The total figure represents approximately $30.2 \%$ of the world population of 7 Billion. Almost $70 \%$ of the world population has not used to the internet (Internet World Statistics, 20I I).

Penetration of Mobile Ttelephony and the Internet in Africa Africa is made up of a few developing countries and a lot of underdeveloped countries. Asia and South America are other continents with developing and underdeveloped countries. However, Africa is chosen because Ghana the country in which the case study will take place is in Africa.

Africa is estimated to have a population of I 05I Million citizens (Population Reference Bureau, 20II). That is approximately $\mathrm{I}$.I billion citizens. Africa has an internet penetration rate of approximately $1 \mathrm{I} .5 \%$. It also makes up $5.6 \%$ percent of the world population using the internet. By 30th June $201 \mathrm{I}$ there were approximately $1 \mathrm{I} 8,848,060$ users of the internet (Internet World Statistics, 20I I).

Earlier in the paper it was mentioned; by October 2010,Africa had 333 million mobile telephony subscribers. This makes up approximately $32.2 \%$ of the total population of Africa using the 2010 population figure of Africa being 1030 Million (Population Reference Bureau, 2010).

The observation made on the impact of mobile telephony and the internet leads to the question of why Africa is lagging behind. This demography of Africa holds the key to this question.

\section{Brief African Demography}

By the year 20II, 39\% of Africans live in urban areas. This means 409890000 Citizens of Africa live in urban areas. Out of these approximately 1.1 billion citizens, $61 \%$ live in rural areas (World Bank, 20I I). From these indicators, comparing the penetration of mobile and internet service in Af- rica, the penetration of the main drivers of ICT is extremely low in Africa due to the non-profitability of investing in ICT and telecom infrastructure in rural areas. Secondly, something has to be done in making sure the potentials of ICT are also present in rural areas, in which in this paper the PPP conceptual model is proposed.

Hence based on this fact, the technology drivers alone have not been able to help the intrusion of telecom and ICTs in rural areas effectively.

\section{Overview of Universal Access Policies}

Telecommunication policies that are geared toward Universal Access have the capacity to develop an ICT driven economy which will in turn lead to the growth of the economy. This fact is based on an argument raised by Neto (2005) which states thus; "......expansion of access to ICTs will generate positive impact on growth is grounded on the perception that investment in telecommunication produces large spillovers (i.e. positive externalities) that improve the efficiency in the economy." These externalities will result in the following as enumerated by Neto (2005):

(I) The generation of many investments in other sectors of the economy.

(2) The reduction of transaction cost in the economy as a whole.

(3) The indirect improvement of human capital and productivity

The idea is borne out of Neto's (2005) attempt to explain the development theories and foundations of Universal Access.

However, there are different models adopted by Governments to ensure the adoption and diffusion of universal access. Some of them include: Access Deficit Charges, Cross Subsidization, Market based reforms (Morten Falch, 2009). Universal Access Obligation (see ICT Regulation Toolkit, Universal Service Obligation, 2010). Privatization of the telecommunication sector, promotion of access via competition, and rate balancing towards cost based prices (Morten Falch, 2009; Kim et al, 2010). Government supports for National backbone development are also some examples by which a telecommunication market can be reformed (see Williams and Botwe, 2010). Liberalization, Deregulation, Commercialization and corporatization and other forms of market based reforms Morten Falch (2009).

Evidently, market based reforms has been a catalyst to the development of other models that will facilitate the growth of the telecommunications market. Examples of these models are Universal Access Fund, Gap model and the Telecenter

ISSN: 07 I8-2724. (http://www.jotmi.org)

Journal of Technology Management \& Innovation (c) Universidad Alberto Hurtado, Facultad de Economía y Negocios. 
initiatives (see Lie, 2004; Oestmann et al, 2008; Townsend et al, 200 I;Townsend et al, 2003; Navas-Sabater, 2002;Townsend and Stern 2006).

However in recent times, Public Private Partnership has been a model with which the public sector employs to attain Universal Access and Service. Although the concept of PPP is muddled with ambiguity in definition, it is simple any form of partnership between the Public and the Private sector to develop infrastructure. This is done in most cases to ensure value for money for the public sector. There are many models of PPP, most are variations on the variation of the Build, design, operate, and maintain concepts (see Blackman and Srivastava, 20I I;Williams and Falch 2012; NCPPP, 20I2). Some models are also viewed from the project ownership point of view with or without who is mandated to finance the project. Traditional PPP has the Private sector financing the PPP projects but in recent times there have been public funds used to supplement private financing. In the telecommunication sector, an example in the Middle East is the development of the Lebanese telecom sector after the civil war. The Build-design-Operate model of PPP was adopted (Jamali, 2004). In the EU where there are notable PPP projects, the provision of subsidy by the German public to enable the development of broadband in rural Germany is another PPP example (The Federal Government's Broadband Strategy, 2008). In Africa there is the EASSy project where there is a PPP between some SADC and Central African countries and a private consortium to develop a transnational fibre optic backbone to connect the SADC area and the Central African areas with the EU as well as granting access to land-locked countries (NEPAD EAfrica Commission, 2012).

\section{Rationale for PPP}

Although it is very glaring that there are other ways of attaining universal Access in a place, PPP is one sure way of enabling the would be network operator enter the market at a reduced cost. This will then translate to the delivery of the network operators' service at to the consumer at a low cost. The main purpose for proposing a PPP is because deploying a cheaper network technology for the rural areas will still be an expensive venture due to the fact that there is little or no market over there. Hence the market has to be 'energized'. Hence if a small network operator can partner with the government knowing that there is a cash flow system in place that will make the business sustainable over time, some investors will be willing to develop a cutting edge business plan to develop in rural areas. This is happening in Brazil, Bolivia, Chile and some few Asian countries like Indonesia (Townsend and Stern 2006; Wismadi and Townsend, 2010).
PPP is flexible, it has the potential of providing efficient delivery of telecom infrastructure development if designed properly and it also has the potential of providing the public sector with value for money (Williams and Falch, 20I2). But the major advantage of PPP from the policy stand point is that the design of a PPP in telecommunications can include the combination of two or more Universal access models. PPP is dynamic. However, a poor design can also lead to undesirable financial consequences to the public sector.

\subsection{Method}

The main method of gathering data was quantitative. In developing this concept interactions were made with policy experts in the academia through unstructured and informal interviews and meetings. Information was also gathered from text books and journals both online and offline to develop the framework. To introduce the framework in order to get feedback, a course on the Political economy of ICT was attended where there was a discussion session on the proposed framework; here useful information on the practicality of this framework was discussed. And also this framework was presented in an ICT conference in Ghana where relevant stakeholders to this framework gathered. Ghana was chosen because it is an African country with sub-Saharan attributes in which many African countries do have. One of them being, a lot of rural areas in which this framework would be of benefit as well. Based on the feedbacks received this paper has been developed. The limitation faced was the inability to meet an African Government official to get the Government perspective to the framework.

\subsection{Proposed Hypothetical PPP Framework}

The primary forces that shape development are the technologies, market and policies (Melody, 20I I). These forces interrelate with each other as shown in the triangle below.

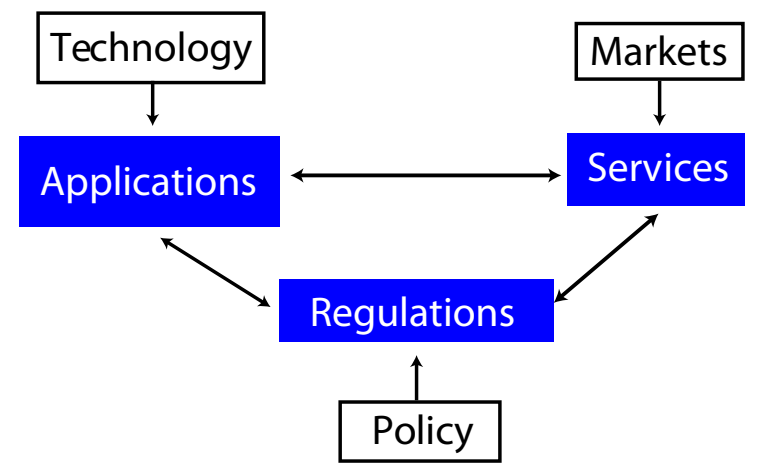

Figure I. Shaping the Development Path Developed using the Actor Network Theory 
As technologies evolve, new applications are created. This new applications lead to new services. These services create market. To ensure public good of the services, new policies may be needed. In the other way round, new markets needs may give rise to new technologies which may need new policies and regulations. And finally, new policies can either promote new markets as well as new technologies. Hence these triangular relationship is comes into operation to enable development. In some cases a component of the triangle may not feature prominently in the development of a sector. This depends on the end result desired by the proponents of the development.

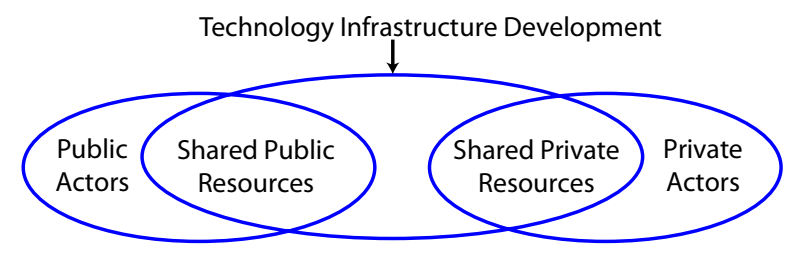

Figure 2. Conceptual Actor Relationship for the cost reduction network extraction.

The proposed PPP fits into this framework. It involves a whole range of actors. At a first glance Actor Network Theory proposed but Bruno Latour (1987) and Michael Callon (1986) both Science and Technology Studies Scholar fits into this model of development. They explain how material and Semiotic networks come together and act as one network. However every actor in the development path-framework can't be captured. Rather only players relevant to the PPP and the cost reduction strategy can be captured. Hence out of the larger network of the development path proposed by Bill Melody comes a sub-set, which one may call a 'cost reduction network extraction'.

The table below identifies the Public and Private actors.

In the next section, a conceptual function of the different stakeholders is outlined.

\section{I Framework Component Design}

The frame work design covers the organizational design and Funding implications.

\section{I.I Organizational Design}

In this sector the various actors in the technology, Market and Policy arms of the development triangle are identified.

(A) Policy Framework:This framework covers the proposed regulatory players and their functions. It also proposes some recommended policy initiatives that will have a great impact in reducing the cost of deployment and access to the telecommunications network.

\section{Policy Stakeholders}

(I) Executive Government: In this framework they mandate the existing regulator or create a new regulator to oversee regulations governing the new Public Private Partnership. They will also oversee access to subsidy for the subscriber from the annual budget.

(2) Parliament: They will make the overall PPP regulations that will be implemented by the Universal Access and Service fund. The policies have to become regulations to become law. To guide their decision, they will have to get input from the regulator a different interest groups to help them fashion an acceptable regulation that will govern the Public Private Partnership.

(3) Regulator: They will also make and implement policy regulations regarding spectrum allocation, licencing, as well as implement parliamentary regulations, Settle disputes and ensure Quality of service of service delivered by the Network operators in the PPP project.

(4) Universal Access and Service Funds: They will partner the small network operator in developing infrastructure. They will also develop a roadmap on modalities of how the money invested can be recouped and how the implementation roadmap will take place.

\begin{tabular}{|l|l|}
\hline Private Actors & Private Actors \\
\hline Executive Government & Small network Providers \\
\hline $\begin{array}{l}\text { Universal Access and Service } \\
\text { Fund }\end{array}$ & $\begin{array}{l}\text { Equipment manufactures/ } \\
\text { Suppliers }\end{array}$ \\
\hline Parliament & NGOs \\
\hline Telecom Regulator & \\
\hline
\end{tabular}

Table I. Conceptual Stakeholder identification

ISSN: 07I 8-2724. (http://www.jotmi.org)

Journal of Technology Management \& Innovation (c) Universidad Alberto Hurtado, Facultad de Economía y Negocios. 
(B) Technology Framework:There are some cheaper ways of deploying small telecom/ICT networks in small remote rural areas. This will depend on the financial ability of the private operator. Even though the PPP will be for small operators, NCA will still decide which operator needs the least subsidy to deliver a low cost service. In this manner, Small network operators are granted licence based on their technical ability and financial ability. For example, if an incoming operator can provide only Long range Wi-Fi Service, and he applies for a Fixed WiMAX licence, that operator can't be granted the licence to operate. This is because he will need too much subsidy from the Universal Access and Service fund to operate.

The following are technologies that can be deployed in rural areas.

(I) Broadband over Power line.This will work most for rural areas that have electricity lines running through their village. It will mostly work for rural areas that are not far from cities.

(2) Long range Wi-Fi networks will be deployed in rural areas by different small telecom companies by small telecom companies. Here the Wi-Fi Point-to-point backbone is used instead of laying fibre optics. They can use a VSAT infrastructure to connect the remote village to the outside world.

(3) Wi-Fi over power line. In this case instead of transmitting broadband over power line, the powerline can be used as a backhaul to wireless communication. An example is using Wi-Fi.

(4) VSAT alone can be used in regions or areas where a lot of telecentres to be constructed.

(5) Telecentres built for rural dwellers that are not able to afford customer premises equipment will also to build by the small network operators to encourage access. There are other possibilities. These techniques are far cheaper than deploying the ubiquitous GSM and UMTS networks. It's easier to recoup the cost of investment for GSM and UMTS in metropolitan areas. In rural areas it is a challenge.

\section{Some advantages of $\mathrm{Wi}-\mathrm{Fi}$}

(I) It is cheaper to deploy Wi-Fi technology than mobile telephony networks.

(2) Wi-Fi spectrum is free in some countries; monthly access charge for VSAT is comparatively low (Williams, 20I I).

(3) ou can reach remote settlements with geographical challenges.
(C) Market Framework:This framework identifies the market players that will participate in the deployment of infrastructure and access to the infrastructure. It also covers the components of the infrastructure deployment, the funding of the scheme, user adoption strategies and the benefits to both the government and the private operator.

\section{Players}

(I) Small network providers like an Internet Service Provider or a small town telecoms company: They will be the main partners with GIFEC for the PPP.To build local content as well as decouple social development from shareholder interests, these small companies should be encouraged by sound regulations to invest in far cheaper network technologies like Wi-Fi etc. in the rural areas. Major companies should be allowed in later when these small companies have grown and created a market.

(2) Equipment manufacturers/ Equipment suppliers: This is an important part of the service delivery. How to get the Customer Premise Equipment (CPE) and the Operators equipment's to the villages at a reduced cost has to be factored into the development of the PPP.

(3) Universal Access and Service Fund to provide funding: They will public funds to the proposed Public Private Partnership by providing subsidy to infrastructure development in the rural areas. They will also work based on funding regulations provided by either the executive government or parliament.

(4) NGOs/Corporate societies: The will be encouraged to run rural telecentres. They can partner as a telecentre outsourcing agent for the small telecom companies or develop their own. With theories like the community of practice, they can ginger the ICT awareness around.

(5) Subscribers:The users will buy the CPEs, for those who can afford it. They will also use the privately owned telecentres for those who can't afford the equipment.

\section{Service Delivery Proposal}

As earlier indicated while making the list of the market stakeholders, it was observed that some people in rural areas will be able to afford CPE's other will not. Hence the development of small telecentres by the small telecom companies is really encouraged to cater for those who can't afford the CPEs. Those who can afford the on the move or remote accessibility options can vie for it. NGOs will be strongly encouraged to help in developing telecentres to harness the ICTs that will be made available.

ISSN: 07 I8-2724. (http://www.jotmi.org) 


\section{User Adoption Strategies}

(I) E-Governance, E-health, E-Education and E-commerce should be used to facilitate usage of the telecentre facilities by the rural dwellers. If Government embraces electronic governance, that will be a major driver for rapid adoption of ICT in the rural areas.

(2) VOIP service can be used as a cheap way of getting contact with the city, especially in areas with no mobile phones.

(3) Government can create an ICT school using this telecentres where graduates on graduation can get a free computer as a gift to start their small IT enterprises. Having learnt the use of E-commerce at the IT school, they can now afford to stay at their homes using the Wi-Fi signals to access the internet to practice what they learnt.

\section{Benefits for the Government}

(I) They are able to build a knowledge economy as well as invest in future tax payers.

(2) They will be able to recoup money from the small fee charged at the IT school, in which the telecentre owners will have a share. They will also be able to recoup money from VAT and foreign exchange on the products produced from the region, when the products are sold in town and especially if the products are exportable.

(3) They will be able to attain their universal access objective.

(4) They will be able to raise the economy of the local area, prompting big telecommunication players to move into the area with more technologies.

\section{Benefit for the Small Telecoms Provider (Private actor)}

(I) They will be able to deliver ICT services to rural areas at a much lower cost than if they were to bear the whole cost.

(2) They will - over time- be able to build a significant market power because many companies who find the cost of production high in town will decide to relocate their production facilities to rural areas.

(3) If they have a good business model, they can as well grow to become a big player.

\subsubsection{Proposed Project Funding Design}

Source of funds for the small network: Banks, equity investors.

Source of funds for the Universal Access and Service Fund: Contributions from large telecoms operators, contribution from international donor agencies, contribution from local NGOs and any other possible way of sourcing for finance.

\section{Adoption Proposal}

Funding to reduce cost of access by subscriber:The Executive Government will be expected subsidize the cost of accessing the network by the subscriber from the budget. This will be the only financial cost the executive government has to bear.

\subsection{Expected Result}

Once the framework is designed by any African Government, certain attributes will be outstanding. These include shared financial obligation by the public and private sector, private sector ownership of the project after the government will recoup its cost over time and pulled out. There will be births to small network providers in villages providing small network solutions. Incentive regulations will enable CPE's into the rural areas at a much reduced cost. The subscriber will be able to afford the service because the shared cost in deploying the small network and the subsidy received from Government to access the network will go a long way in reducing the cost the subscriber would access the network.

\subsection{Conclusion}

The argument that markets in itself can enable the universal access of telecommunication/ICT Services unfortunately has not worked for rural areas in Africa. Hence the need for a pragmatic step to curb cost accrued to deploying telecommunication/ICT services in rural areas is now urgent. Although the concept and effectiveness of Public Private Partnership is still under the scrutiny of political economist worldwide, in this paper, the argument here is simple: Let's take advantage of the flexibility of PPP to access rural areas. It is not so much about whether the Private sector should fund the whole project alone or whether the government should play a peripheral role. It is all about the sharing and the management of resources by both the public and private sector in a way that will help rural areas in third world countries.

The institutional structure needed to build this framework in order to develop telecoms/ICT exists in many African

ISSN: 07I 8-2724. (http://www.jotmi.org) 
countries. All it takes is an innovation in relationships and entities within the ecosystem. With the development part analyzed so far, it is the conviction of this research that barring any limitation that may arise with this Public Private Partnership proposal, it is a path way to rural telecommunication/ICT development worth considering.

This structure has the potential of enabling broadband internet in rural areas. The research into the dynamics framework is still ongoing at Aalborg University Denmark.

\section{Glossary}

CDMA Code Division Multiple Access

CPE Customer Premise Equipment

GIFEC Ghana Investment Fund for Electronic Communications

HSPA High Speed Packet Access

ICT Information Communications Technology

ITU International Telecommunications Union

LTE Long Term Evolution

NGO Non-Governmental Organization

PDP Public-Private Product Development Partnership)

PPP Public Private Partnership

PRB Population Reference Bureau

PSPP Public Social Private Partnership

VAT Value Added tax

VOIP Voice over Internet Protocol

Wi-Fi Wireless Fidelity

WIMAX Worldwide Interoperability for Microwave Access

\section{References}

ALOZIE, N., Akpan-obong, P., William, F. (20I I). Sizing up information and communications technologies as agents of political development in sub-Saharan Africa'. Telecommunications Policy. 35 (20II) 752-763.

BLACKMAN, C., \& Srivastava, L. (Eds.) (20II).Telecommunications Regulation Handbook. InfoDev. World Bank Publication.

CALLON, M. (1986). Some Elements of a Sociology of Translation: Domestication of the Scallops and the Fishermen of St Brieuc Bay. Pp. 196-233 in Power,Action and Belief:A New Sociology of Knowledge, edited by John Law. London: Routledge \& Kegan Paul.

CHAUVILLE, N., Damien, C and Van Wyk, B. (2005).WiMAX access over GSM/GPRS in rural areas, in Proceedings of Electron Devices for Microwave and Optoelectronic Applications, 2004. 12th International Symposium, 8-9 Nov.2004. 106-109. IEEE Conference Publications
DIMRI, D.P. (2003). RURAL TELEPHONY:Will There Be Will. Voice\&Data Magazine. .http://voicendata.ciol.com/content/ policy/I03 I I I20 I asp. [Accessed September, 20 I I].

FALCH, M. (2009); Universal Service and Digital Divide, Centre for Communications Media and Information technology, November 2009

HUGHES, O (1998). Public Management and Administration. St Martin's Press, New York, Ny

ITU (2010). Key Global Telecom Indicators for the World Telecommunication Service Sector.http://www.itu.int/ITUD/ict/statistics/at_glance/KeyTelecom.html . [Accessed September, 20II]

Internet World Statistics (20II).http://www.internetworldstats.com/top20.htm. [Accessed September, 20I I]

JAMALI, D. (2004). Success and failure mechanisms of public private partnerships (PPPs) in developing countries: Insights from the Lebanese context. The International Journal of Public Sector Management. 17(5), 4I4-430

KAS, K. (2008).The Global Adoption and Diffusion of Mobile Phones. Harvard University Publication.http://pirp.harvard. edu/pubs_pdf/kalba/kalba-p08-I.pdf. [Accessed September, 20II]

KIM,Y., Kelly,T., Raja, S. (2010). Building broadband: Strategies and policies for the developing world. Global Information and communication department Jan, 2010 Report. World Bank.

LATOUR, B. (1987). Science in Action: How to Follow Scientists and Engineers Through Society (Milton Keynes: Open University Press).

LIE, E. (2007). Next Generation Networks and Universal Access, the challenges ahead. Global Symposium for Regulators. International Telecommunications Union . http://www. itu.int/ITU-D/treg/Events/Seminars/GSR /GSR07/ discussion_papers/Eric_Lie_universal_service.pdf . [Accessed June, 20II]

MELODY,W. (20I I). Political Economy of ICT,Lirne.net

Mobile Thinking (20I I). Global mobile statistics 20I I.Available on the internet. http://mobithinking.com/mobile-marketing-tools/latest-mobile-stats. [Accessed September, 20I I]

NAVAS-SABATER. (2002). The "Gaps" model and universal access. Cited by Arturo Muente-kunigami in World Bank

ISSN: 07 I8-2724. (http://www.jotmi.org) 
Blogs. http://blogs.worldbank.org/ic4d/the-gaps-model-anduniversal-access. [Accessed June, 20II]

NCPPP (20I2).Types of Public-Private Partnerships. http:// www.ncppp.org/howpart/ppptypes.shtml

NETO, C. (2005). Development Theory and Foundations of Universal Access Policies, Yale Law School

NEPAD e-Africa Commission. (20I2). NEPAD ICT Broadband Infrastructure Network. http://www.eafricacommission.org/projects//26/nepad-ict-broadband-infrastructurenetwork.

Oestmann, S., Dymond,A. (2008). Universal Access and Service. Module 4 of ICT regulation toolkit, Intelecon research and consultancy. http://www.ictregulationtoolkit.org/en/ Sections.aspx\#3 |26\#. [Accessed June, 20II]

Population Reference Bureau (2010). PRB's 2010 World Population Data Sheet http://www.prb.org/pdf10//0wpds_ eng.pdf. [Accessed September, 20I I]

Population Reference Bureau (20II). 20II World Population Data Sheet. http://www.prb.org/pdfl I/20I I populationdata-sheet_eng.pdf. [Accessed September, 20I I]

Practice Note. (20II). Guidelines to Universal Access and Universal Service in Western Africa. InfoDev Publication. http://www.ictregulationtoolkit.org/en/PracticeNote.3079. html. [Accessed June, 20II]

TOWNSEND, D. (2003). Model Universal Access Policies: Entrepreneurial Strategies for Stimulating Telecommunications Market Development, DTNA Report

TOWNSEND, D. and Stern, P. (2006). New Models for Universal Access in Latin America. Infodev. World Bank report. http://www.ictregulationtoolkit.org/en/Publication.35I I. html [Accessed September, 20I I].

The Federal Government's Broadband Strategy (2009). http://www.bmwi.de/English/Redaktion/Pdf/broadband-strat egy,property=pdf,bereich $=$ bmwi,sprache $=$ en, $r w b=$ true.pdf. [Accessed June, 20II]

Universal Service Obligation.(2010). InfoDev Publication. http://www.ictregulationtoolkit.org/en/Section. 1740.html, ICT Regulation Toolkit [Accessed June, 20I I].

WILLIAMS, I. (20I I). Telecom Policy Innovation: the Role of Free Spectrum and Telecommunication Development in Rural Ghana. Journal for Technology Management and Innovation.Vol 6, No 3 PP 93-104
WILLIAMS, I and Botwe Y. (20I0). Analysis of the Proposed Ghana Broadband Strategy, Munich, GRIN Publishing GmbH

WILLIAMS, I., and Falch, M. (20I2). Public Private Partnerships and Next Generation Networks. In A.M. Hadjiantonis and B. Stiller (Eds.):Telecommunication Economics, (pp. 100107). LNCS 7216, Springer.

World Bank (20II). Urban Development. Available on the internet. http://data.worldbank.org/topic/urban-development. [Accessed September, 20I I]

WISMADI,A, and Townsend, D. (2010) .Rural ICT Policy Advocacy, Knowledge sharing and capacity building: Country case study Indonesia. ADB/International Telecommunications Union. 
J.Technol. Manag. Innov. 2012,Volume 7, Issue 2

ISSN: 07I8-2724. (http://www.jotmi.org)

Journal of Technology Management \& Innovation @ Universidad Alberto Hurtado, Facultad de Economía y Negocios. 